\title{
Restless Legs Syndrome in Pregnant Thai Women: Prevalence, Predictive Factors, and Natural Course
}

\author{
Supakorn Panvatvanich ${ }^{\mathrm{a}}$ \\ Praween Lolekha ${ }^{\mathrm{a}, \mathrm{b}}$ \\ ${ }^{a}$ Neurology Division, \\ Department of Internal Medicine and \\ ${ }^{\mathrm{b}}$ Stroke and Neurodegenerative Diseases \\ Research Unit, Thammasat University \\ (Rangsit Campus), Pathumthani, \\ Thailand
}

\begin{abstract}
Background and Purpose Restless legs syndrome (RLS) is a common sleep-related neurological disorder that affects the quality of sleep. This study aimed to estimate the prevalence, predictive factors, and natural course of RLS, and its effect on sleep quality in pregnant Thai women.

Methods A cross-sectional study that included 214 pregnant women was performed. RLS was diagnosed according to the revised criteria of the International RLS Study Group (IRLSSG). General demographic and antenatal-care data were reviewed. Scores on the Thai versions of the Epworth Sleepiness Scale (ESS), Pittsburgh Sleep Quality Index, and the IRLSSG Rating Scale were determined.
\end{abstract}

Results RLS was diagnosed in 24 of the pregnant women (11.2\%): 4.2\%, 25.0\%, and 70.8\% in the first, second, and third trimesters, respectively. Multiple logistic regression analysis revealed that a hemoglobin level $(\mathrm{Hb})$ less than $11 \mathrm{~g} / \mathrm{dL}$ [odds ratio $(\mathrm{OR})=3.21,95 \% \mathrm{CI}=1.27-$ 8.13] and a history of RLS (OR=16.62, 95\% CI=1.52-181.32) were associated with RLS during pregnancy. Subjects with RLS significantly had higher Thai-ESS scores $(p<0.01)$. All subjects with RLS had severe symptoms that subsided within 1 week after delivery. No immediate labor complication was associated with RLS.

Conclusions Our study has confirmed a high prevalence of RLS and its impacts on sleep in pregnant women. An $\mathrm{Hb}$ of less than $11 \mathrm{~g} / \mathrm{dL}$ and a history of RLS are predictive factors for RLS developing during pregnancy. Pregnancy-related RLS has a benign course and usually disappears within 1 week after delivery.

Key Words restless legs syndrome, sleep disorder, pregnancy, Thai, anemia.

\section{INTRODUCTION}

Restless legs syndrome (RLS) is a sleep-related neurological disorder characterized by an urge to move the legs due to unpleasant sensations. RLS usually occurs at rest, worsens at night, and is relieved by movement of the affected limbs. ${ }^{1}$ RLS was also known as WillisEkbom disease, named after Dr. Thomas Willis, an English physician whose first case report was published in 1685, and Dr. Karl Axel Ekbom, a Swedish neurologist who introduced this term for the disease and described how to diagnosis it in $1945 .{ }^{2}$

The standard diagnostic criteria of RLS were first proposed by the International RLS Study Group (IRLSSG) in $1995^{3}$ and revised in $2002 .{ }^{1}$ RLS commonly occurs secondary to various medical conditions such as end-stage renal disease, peripheral neuropathy, iron deficiency, and pregnancy. ${ }^{4}$ The impact of RLS can be mild to severe, with adverse effects on sleep quality, cognitive functions, mood, and quality of life. ${ }^{5}$

While pregnancy-related RLS has been well described, its prevalence, natural course, and pathophysiology have not been identified. ${ }^{6}$ Recent systemic reviews found that the prevalence of RLS during pregnancy ranges between $11 \%$ and $34 \%,{ }^{7-13}$ which is typically

( $)$ This is an Open Access article distributed under the terms of the Creative Commons Attribution Non-Commercial License (https://creativecommons.org/licenses/by-nc/4.0) which permits unrestricted non-commercial use, distribution, and reproduction in any medium, provided the original work is properly cited. 
two to threefold higher than in general nonpregnant women. ${ }^{4}$ Furthermore, the prevalence of RLS during pregnancy was reported to peak in the third trimester and may be related to the parity. ${ }^{9}$ These data were assessed from the pooled prevalence mostly in American, European, and East Asian countries, and have been lacking from the Southeast Asia. ${ }^{13}$

Possible mechanisms underlying the pathophysiology of pregnancy-related RLS have been proposed. These include iron and folate deficiency due to a dilution effect and utilization for fetal development, hormonal changes, psychological conditions, lumbosacral radiculopathy, and peripheral venous congestion in pregnancy. ${ }^{4}$ Since RLS has a negative impact on the quality of sleep, RLS may result in a higher risk of pregnant women developing pregnancy and delivery complications, and of adverse effects on fetal development. ${ }^{5,14}$

A population-based epidemiological study has not been performed previously among pregnant Thai women. Therefore, the primary aim of this study was to estimate the prevalence, natural course, and predictive factors of RLS in pregnant Thai women. The secondary aim was to determine the effect of RLS on sleep quality in pregnant women.

\section{METHODS}

This cross-sectional retrospective study enrolled pregnant Thai women who attended Thammasat University delivery unit from October to December 2017. Three hundred and fifty-four pregnant women older than 15 years were interviewed. Of those, 131 pregnant women were excluded due to non-Thai citizenship or no data available for the history of antenatal care. Women who were admitted to a private ward or had severe pregnancy complications such as preeclampsia and miscarriage were excluded. Finally, 214 pregnant women were enrolled. All subjects received regular obstetrical care by their physician, and no alteration of obstetrical care was recommended or mandated for any of them. Our study was approved by the Human Research Ethics Committee of Thammasat University (IRB No. MTU-EC-IM-0-046/60).

The study participants were diagnosed with RLS in a faceto-face interview with a neurologist during their admission for labor and delivery care. RLS was diagnosed according to the revised criteria of the IRLSSG. ${ }^{1}$ General demographic data were collected, including the antenatal-care history, routine blood test results, and past medical illnesses. Scores on the Thai versions of the Epworth Sleepiness Scale (ESS) and Pittsburgh Sleep Quality Index (PSQI) were determined. ${ }^{15}$ Pregnant women who fulfilled the IRLSSG diagnosis criteria were diagnosed as having pregnancy-related RLS. RLS-positive participants were also questioned about the onset, duration, and severity of RLS. The IRLSSG Rating Scale (IRLS) was used to evaluate the severity of RLS. ${ }^{16}$ Furthermore, participants diagnosed as having pregnant-related RLS were followed for postpartum symptoms and complications for 6 weeks.

\section{Maternal and neonatal outcome data}

The antepartum medical records of all enrolled participants and their newborns were collected, including delivery type, birthweight and sex of the newborn, Apgar scores at 1 and 5 minutes, and immediate postpartum complications. The continuous variables were summarized as mean $\pm S D$ values, and categorical variables were summarized as number (percentage) values. Quantitative data were compared using student's $t$-test, and qualitative data were compared using the $\chi^{2}$ test. Multiple regression analysis was applied to identify significant predictive factors of RLS. A $p$ value of less than 0.05 was considered statistically significant.

\section{RESULTS}

This study included 214 pregnant women aged $28.60 \pm 6.52$ years and with an age range of 15-45 years. Demographic and clinical characteristics of the study participants with and without RLS are provided in Table 1.

\section{Comparisons of participants with and without RLS during pregnancy}

RLS was diagnosed in 24 of the pregnant women, indicating an RLS prevalence rate of $11.2 \%$. Comparison of the data among the RLS and non-RLS groups revealed no significant differences in the age, body mass index, gravidity, parity, and maternal and childbearing history. In addition, personal behaviors such as the history of smoking, alcohol, and coffee consumption did not differ significantly between the two groups. The hemoglobin level $(\mathrm{Hb})$ during pregnancy was significantly lower in the RLS group than in the non-RLS group $(11.21 \pm 1.11$ vs. $11.83 \pm 1.22 \mathrm{~g} / \mathrm{dL}, p=0.02)$. The hematocrit and mean corpuscular volume were also lower in the RLS group; however, the differences were not statistically significant. The incidence rates of anemia during pregnancy (defined as an $\mathrm{Hb}$ of less than $11 \mathrm{~g} / \mathrm{dL}$ ), thyroid disease, previous history of RLS, and family history of RLS were significantly higher in the RLS group $(p<0.01)$ (Table 1). Multiple logistic regression analysis revealed that $\mathrm{Hb}$ less than $11 \mathrm{~g} / \mathrm{dL}$ [odds ratio $(\mathrm{OR})=$ $3.21,95 \% \mathrm{CI}=1.27-8.13$ ] and a history of RLS (OR=16.62, $95 \% \mathrm{CI}=1.52-181.32)$ were associated with RLS during pregnancy (Table 2).

In terms of sleep quality, $75 \%$ of pregnant Thai women were considered as poor sleepers according to the Thai-PSQI global score. ${ }^{15}$ Comparing the data between the RLS and nonRLS groups revealed no significant differences regarding Thai- 
Table 1. Demographic and clinical characteristics of the study subjects with and without RLS

\begin{tabular}{|c|c|c|c|c|}
\hline \multirow{2}{*}{ Characteristic } & \multirow{2}{*}{$\begin{array}{c}\text { All subjects } \\
(n=214)\end{array}$} & \multicolumn{2}{|c|}{ RLS during pregnancy } & \multirow[b]{2}{*}{$p$} \\
\hline & & No $(n=190)$ & Yes $(n=24)$ & \\
\hline Age, years & $28.60 \pm 6.52$ & $28.73 \pm 6.53$ & $27.58 \pm 6.54$ & 0.42 \\
\hline BMI, before pregnancy & $22.55 \pm 4.46$ & $22.58 \pm 4.55$ & $22.31 \pm 3.69$ & 0.75 \\
\hline BMI, third trimester & $27.69 \pm 4.67$ & $27.73 \pm 4.80$ & $27.43 \pm 3.58$ & 0.71 \\
\hline $\mathrm{Hb}, \mathrm{g} / \mathrm{dL}$ & $11.76 \pm 1.22$ & $11.83 \pm 1.22$ & $11.21 \pm 1.11$ & 0.02 \\
\hline Hematocrit, \% & $35.98 \pm 3.53$ & $36.12 \pm 3.60$ & $34.94 \pm 2.79$ & 0.13 \\
\hline$M C V, f L$ & $81.72 \pm 8.68$ & $81.78 \pm 8.90$ & $81.21 \pm 6.83$ & 0.76 \\
\hline Multigravida & 83 (38.8) & 74 (38.9) & $9(37.5)$ & 0.89 \\
\hline Multiparity & $45(21.0)$ & $40(21.1)$ & $5(20.8)$ & 0.98 \\
\hline History of abortion & 34 (15.9) & $29(15.3)$ & $5(20.8)$ & 0.48 \\
\hline Diabetes mellitus & $10(4.7)$ & $9(4.7)$ & $1(4.2)$ & 0.90 \\
\hline Thyroid disease & $1(0.5)$ & 0 & $1(4.2)$ & $<0.01$ \\
\hline Hypertension & $10(4.7)$ & $8(4.2)$ & $2(8.3)$ & 0.37 \\
\hline Anemia (Hb <11 g/dL) & $45(21.0)$ & $34(17.9)$ & $11(45.8)$ & $<0.01$ \\
\hline Past smoking & $13(6.1)$ & $11(5.8)$ & $2(8.3)$ & 0.62 \\
\hline Past alcohol & $27(12.6)$ & $23(12.1)$ & $4(16.7)$ & 0.53 \\
\hline Past caffeine & $43(20.1)$ & 37 (19.5) & $6(25)$ & 0.52 \\
\hline History of RLS & $4(1.9)$ & $1(0.5)$ & $3(12.5)$ & $<0.01$ \\
\hline Family history of RLS & $1(0.5)$ & 0 & $1(4.2)$ & $<0.01$ \\
\hline Delivery complications & 35 (16.4) & $21(11.1)$ & $3(12.5)$ & 0.58 \\
\hline Female newborn & $123(57.5)$ & $112(58.9)$ & $11(45.8)$ & 0.22 \\
\hline Preterm labor & $36(16.8)$ & $31(16.3)$ & $5(20.8)$ & 0.58 \\
\hline Cesarean section & $68(31.8)$ & $61(32.1)$ & 7 (29.2) & 0.77 \\
\hline Apgar score & $8.84 \pm 0.73$ & $8.86 \pm 0.73$ & $8.71 \pm 0.75$ & 0.35 \\
\hline Birthweight, g & $3001.1 \pm 463.1$ & $3013.8 \pm 461.7$ & $2899.8 \pm 471.8$ & 0.26 \\
\hline
\end{tabular}

Data are mean \pm SD or $n(\%)$ values.

BMI: body mass index, $\mathrm{Hb}$ : hemoglobin level, MCV: mean corpuscular volume, RLS: restless legs syndrome.

Table 2. Results from a multiple logistic regression model with variables for RLS during pregnancy

\begin{tabular}{lccccccc}
\hline \multicolumn{1}{c}{ Variable } & B & SE & Wald & df & $\boldsymbol{p}$ & OR & 95\% Cl \\
\hline Constant & -2.527 & 0.293 & 74.500 & 1 & $<0.001$ & 0.080 & \\
Anemia $(\mathrm{Hb}<1 \mathrm{~g} / \mathrm{dL})$ & 1.166 & 0.474 & 6.040 & 1 & 0.014 & 3.209 & 1.27 to 8.13 \\
History of RLS & 2.810 & 1.219 & 5.312 & 1 & 0.021 & 16.616 & 1.52 to 181.32 \\
\hline
\end{tabular}

$\mathrm{Hb}$ : hemoglobin level, OR: odds ratio, RLS: restless legs syndrome, SE: standard error.

PSQI sleep quality, latency, duration, habitual sleep efficiency, disturbances, use of medication, daytime dysfunction subscore, or global score $(8.63 \pm 3.71$ vs. $7.77 \pm 3.21, p=0.26)$. Subjects with RLS reported a longer sleep onset latency than those without RLS, but the difference was not statistically significant ( $54.79 \pm 58.08$ vs. $40.55 \pm 36.55, p=0.09)$. Thai-ESS scores were significantly higher in the RLS group (3.04 \pm 1.49 vs. $1.54 \pm 1.33, p<0.001$ ) (Table 3 ) and were associated with gravidity, parity, history of RLS, and alcohol consumption. However, only the presence of RLS during pregnancy was associated with a high Thai-ESS score in a multivariate analysis (Table 4).

\section{Natural course of RLS during pregnancy}

The proportions of participants having RLS during different trimesters among the 24 pregnant Thai women enrolled in the study were as follows: $4.2 \%, 25.0 \%$, and $70.8 \%$ in the first, second, and third trimesters, respectively. All of the subjects who developed RLS during pregnancy reported that their symptoms had persisted through the third trimester, with a duration of $2.08 \pm 1.25$ months (range $=1-6$ months). The demographic variables did not differ significantly among subjects with RLS starting in the first, second, and third trimesters. All subjects with RLS scored within the range of severe symptom severity according to the IRLS (range $=22-30) .{ }^{16}$ There was no significant factor related to the severity of symptoms among the RLS subjects. After delivery, eight partici- 
pants (33.3\%) continued experiencing RLS symptoms, indicating that the prevalence of RLS decreased significantly to $3.7 \%$. The symptoms disappeared within a few days in seven of these participants, and within 1 week in the eighth. None of the subjects required pharmacological treatment other than the standard iron and supplements during antenatal-care visits. There were no intergroup differences in delivery type, complications, Apgar scores, birthweight, or sex of the newborn.

\section{DISCUSSION}

The prevalence of pregnancy-related RLS found in this study is consistent with previous reports of $11.2 \%$ to $12.3 \%$ in the Chinese population, ${ }^{9,17}$ which is lower than the prevalence found in pregnant European and Scandinavian women., ${ }^{8}$ Based on a recent systemic review and meta-analysis, this could be the first report on the prevalence in the Southeast Asia. ${ }^{13}$ The differences in prevalence can be attributed to several factors: 1) the ethnicity of the study population, since the

Table 3. Scores on the Thai versions of the PSOI and ESS in the RLS and non-RLS groups

\begin{tabular}{lccc}
\hline \multicolumn{1}{c}{$\begin{array}{c}\text { Sleep-disorder } \\
\text { parameter }\end{array}$} & \multicolumn{2}{c}{ RLS during pregnancy } & \\
\cline { 2 - 3 } & No $(\boldsymbol{n}=\mathbf{1 9 0})$ & Yes $(\boldsymbol{n}=\mathbf{2 4})$ & \\
\hline Sleep quality & $1.42 \pm 0.85$ & $1.38 \pm 1.06$ & 0.84 \\
Sleep latency & $1.48 \pm 1.10$ & $1.83 \pm 1.17$ & 0.14 \\
Sleep duration & $1.29 \pm 0.96$ & $1.46 \pm 0.89$ & 0.42 \\
\hline Habitual sleep efficiency & $1.74 \pm 1.12$ & $1.92 \pm 1.18$ & 0.46 \\
Sleep disturbances & $1.27 \pm 0.46$ & $1.38 \pm 0.50$ & 0.31 \\
Use of sleeping medication & 0.00 & 0.00 & - \\
\hline Daytime dysfunction & $0.61 \pm 0.69$ & $0.75 \pm 0.68$ & 0.35 \\
Thai-PSOl global score & $7.77 \pm 3.21$ & $8.63 \pm 3.71$ & 0.26 \\
Thai-PSOl global score $>5$ & $143(75.3)$ & $17(70.7)$ & 0.68 \\
\hline Total sleep duration, hours & $5.91 \pm 1.54$ & $5.67 \pm 1.09$ & 0.34 \\
Sleep onset latency, minutes & $40.55 \pm 36.55$ & $54.79 \pm 58.08$ & 0.09 \\
Thai-ESS score & $1.54 \pm 1.33$ & $3.04 \pm 1.49$ & $<0.01$ \\
\hline
\end{tabular}

Data are mean \pm SD or $n(\%)$ values.

ESS: Epworth Sleepiness Scale, PSOl: Pittsburgh Sleep Quality Index, RLS: restless legs syndrome. general prevalence of RLS is reportedly lower in Asians than in Caucasians, 2) women with mild RLS symptom severity may remain undiagnosed due to them being unaware of their symptoms, and 3) the prevalence rate in our study is based on interviews performed during the third trimester.

Regarding risk factors, our study found that anemia and a previous history of RLS were risk factors for developing RLS during pregnancy, which is similar to the findings of previous studies., ${ }^{4,9}$ This reflects the underlying pathophysiology of iron and folate depletion during pregnancy. Since the symptoms disappeared rapidly after delivery, the depletion may be the result of a dilution effect rather than an absolute iron and folate deficiency. Future studies should evaluate the serum levels of iron and ferritin in general pregnancies, and women who develop iron deficiency anemia during pregnancy should be adequately treated with iron supplementation. Other hypotheses associated with the pathophysiology of RLS during pregnancy such as genetic susceptibility, hormonal changes, or psychological conditions were not evaluated in this study.

Concerning sleep quality, the subjects with RLS had a relatively higher Thai-PSQI global score and longer sleep onset latency than those without RLS, but the difference was not statistically significant. This may have resulted from the high incidence of poor sleepers (Thai-PSQI global score $>5$ ) among general pregnant Thai women. Sleep problems including in conditions other than RLS during pregnancy should be explored, and there should be a focus on providing education about healthy sleep behaviors. Excessive daytime sleepiness may occur during pregnancy and be related to the RLS frequency as a result of poor nighttime sleeping. ${ }^{17}$ In our study, pregnant women with RLS were more likely to experience daytime sleepiness than were those without RLS, but none of them had significant problems with daytime sleepiness.

Regarding pregnancy-associated complications and delivery outcomes, no significant differences were seen between the RLS and non-RLS groups. Since RLS during pregnancy is transient and has a benign course, providing information about RLS and natural course to pregnant women are needed.

We acknowledge that our present study has some limita-

Table 4. Results from a multiple linear regression model of a high Thai-ESS score

\begin{tabular}{lccccc}
\hline & B & SE & $\boldsymbol{t}$ & $\boldsymbol{p}$ & $\mathbf{9 5 \%} \mathbf{C l}$ \\
\hline Constant & 1.809 & 0.268 & 6.760 & $<0.001$ & \\
Gravidity & -0.055 & 0.204 & -0.271 & 0.786 & -0.46 to 0.35 \\
Parity & -0.273 & 0.236 & -1.153 & 0.250 & -0.74 to 0.19 \\
Alcohol & 0.432 & 0.273 & 1.582 & 0.115 & -0.11 to 0.97 \\
History of RLS & 1.143 & 0.700 & 1.631 & 0.104 & -0.24 to 2.52 \\
RLS during pregnancy & 1.353 & 0.298 & 4.546 & $<0.001$ & 0.77 to 1.94 \\
\hline
\end{tabular}

ESS: Epworth Sleepiness Scale, RLS: restless legs syndrome, SE: standard error. 
tions. First, our study based on one center and the number of participants was limited. Even though the study population was adequate to estimate the RLS prevalence, it was too small to identify the certain predictive factors of RLS during pregnancy. A prospective, multicenter registry with a larger sample size should be considered in the future. Second, the diagnosis of RLS was based on the recalled data during the third trimester of pregnancy. Third, the levels of iron and ferritin were not evaluated in the study. Further research on iron metabolism and pregnancy-related RLS pathophysiology is needed. Fourth, major pregnancy and delivery complications were excluded from the study. Last, environmental factors that could affect the quality of sleep were not controlled. A standard sleep monitoring with polysomnography should be considered.

In conclusion, our study confirmed a high prevalence of RLS and its impacts on sleep in pregnant Thai women. Anemia and history of RLS are predictors of developing RLS during pregnancy. RLS is commonly found in the second to third trimesters of pregnancy. In general, pregnancy-related RLS is benign. The symptoms usually transient and disappear within a few days after delivery. There was no immediate labor or newborn complications associated with RLS.

\section{Conflicts of Interest}

The authors have no financial conflicts of interest.

\section{Acknowledgements}

We thank Assoc. Prof. Atiwut Kamudhamas, Department of Obstetrics \& Gynecology, Faculty of Medicine, Thammasat University and all the participants who took part in the questionnaire survey.

\section{REFERENCES}

1. Allen RP, Picchietti D, Hening WA, Trenkwalder C, Walters AS, Montplaisi J. Restless legs syndrome: diagnostic criteria, special considerations, and epidemiology. A report from the restless legs syndrome diagnosis and epidemiology workshop at the National Institutes of Health. Sleep Med 2003;4:101-119.
2. Ekbom KA. Restless legs. Acta Med Scand 1945;158 Suppl:4-122.

3. Walters AS. Toward a better definition of the restless legs syndrome. The international restless legs syndrome study group. Mov Disord 1995; 10:634-642.

4. Srivanitchapoom P, Pandey S, Hallett M. Restless legs syndrome and pregnancy: a review. Parkinsonism Relat Disord 2014;20:716-722.

5. Ghanei Gheshlagh R, Lanjavani T, Lazari N, Moslemi B. Comparison of the quality of life in pregnant women with and without restless legs syndrome. J Clin Nurs Midwifery 2014;3:54-61.

6. Li LH, Chen HB, Zhang LP, Wang ZW, Wang CP. A community-based investigation on restless legs syndrome in a town in China. Sleep Med 2012;13:342-345.

7. Manconi M, Govoni V, De Vito A, Economou NT, Cesnik E, Casetta I, et al. Restless legs syndrome and pregnancy. Neurology 2004;63:10651069.

8. Neau JP, Marion P, Mathis S, Julian A, Godeneche G, Larrieu D, et al. Restless legs syndrome and pregnancy: follow-up of pregnant women before and after delivery. Eur Neurol 2010;64:361-366.

9. Shang X, Yang J, Guo Y, Ma S, Jia Z, Xue R. Restless legs syndrome among pregnant women in China: prevalence and risk factors. Sleep Breath 2015;19:1093-1099.

10. Sikandar R, Khealani BA, Wasay M. Predictors of restless legs syndrome in pregnancy: a hospital based cross sectional survey from Pakistan. Sleep Med 2009;10:676-678.

11. Suzuki K, Ohida T, Sone T, Takemura S, Yokoyama E, Miyake T, et al. The prevalence of restless legs syndrome among pregnant women in Japan and the relationship between restless legs syndrome and sleep problems. Sleep 2003;26:673-677.

12. Uglane MT, Westad S, Backe B. Restless legs syndrome in pregnancy is a frequent disorder with a good prognosis. Acta Obstet Gynecol Scand 2011;90:1046-1048.

13. Chen SJ, Shi L, Bao YP, Sun YK, Lin X, Que JY, et al. Prevalence of restless legs syndrome during pregnancy: a systematic review and meta-analysis. Sleep Med Rev 2018;40:43-54.

14. Chang JJ, Pien GW, Duntley SP, Macones GA. Sleep deprivation during pregnancy and maternal and fetal outcomes: is there a relationship? Sleep Med Rev 2010;14:107-114.

15. Sitasuwan T, Bussaratid S, Ruttanaumpawan P, Chotinaiwattarakul W. Reliability and validity of the Thai version of the Pittsburgh sleep quality index. J Med Assoc Thai 2014;97 Suppl 3:S57-S67.

16. Walters AS, LeBrocq C, Dhar A, Hening W, Rosen R, Allen RP, et al. Validation of the international restless legs syndrome study group rating scale for restless legs syndrome. Sleep Med 2003;4:121-132.

17. Liu G, Li L, Zhang J, Xue R, Zhao X, Zhu K, et al. Restless legs syndrome and pregnancy or delivery complications in China: a representative survey. Sleep Med 2016;17:158-162. 